\title{
Computer simulation for predicting tractor engine overloading for tillage operations
}

\author{
SHRIKANT S. SADAVARTE AND MAHESH R. PATIL
}

\begin{abstract}
The primary purpose of agricultural tractors, especially those in the middle to high power range, is to perform field work. Tractor manufacturer needs prediction of tractor field performance data in the tractor design stage itself so that they can optimize the transmission with the engine to give better performance. Engine speed prediction model was developed using Budni tractor test data. Developed engine speed prediction model for 10 engine model was compared with actual data of engine speed, it was found that for all engine models $\mathrm{R}^{2}$ (co-efficient of determination) between predicted and actual engine speed was greater than 0.98 . So developed empirical equations can be used in software for predicting engine speed. The field experiments were conducted using a tractor with three different implements viz., 3-bottom mould board plough, 11-tyne cultivator and offset disc harrow. For each operation, the performance parameters such as draft, slip, depth, engine speed and fuel consumption were measured at different combinations of gear and throttle positions. Software in visual basic was developed to predict tractor engine overloading (engine speed drop) for field operations (MB plough, cultivator and disc harrow). The developed software was validated using field data collected in Kanchipuram, Tamil Nadu. For field operation with 2 WD tractor equipped with bias-ply tires and attached with cultivator the deviation of software predicted engine speed (rpm) drop was -16.47 to 26.92 per cent and for draft was -11.07 to 4.65 per cent. For field test with offset disc harrow the deviation of software predicted engine speed (rpm) drop was -17.44 to 15.38 per cent and for draft was -10.98 to 4.76 per cent. For field operation with MB Plough the deviation of software predicted engine speed (rpm) drop was 18.48 to 21.52 per cent and for draft -12.01 to -3.75 per cent.
\end{abstract}

KEY WORDS : Tractor engine overloading, Engine speed prediction model, Visual basic, Engine overloading

How to cite this Article : Sadavarte, Shrikant S. and Patil, Mahesh R. (2015). Computer simulation for predicting tractor engine overloading for tillage operations. Engg. \& Tech. in India, 6 (2) : 80-88. 